\title{
Preoperative alpha-fetoprotein (AFP) in hepatocellular carcinoma (HCC): is this 50-year biomarker still up-to-date?
}

\author{
Fabrice Muscari, Charlotte Maulat \\ Department of Digestive Surgery and Transplantation, Toulouse University Hospital, Toulouse, France \\ Correspondence to: Dr. Charlotte Maulat, MD. Department of digestive surgery and transplantation, Toulouse University Hospital, 1 avenue Jean \\ Poulhès, 31400 Toulouse, France. Email: charlotte.maulat@gmail.com. \\ Provenance: This is an invited article commissioned by the Editorial Office of Translational of Gastroenterology and Hepatology. \\ Comment on: Chan MY, She WH, Dai WC, et al. Prognostic value of preoperative alpha-fetoprotein (AFP) level in patients receiving curative \\ hepatectomy- an analysis of 1,182 patients in Hong Kong. Transl Gastroenterol Hepatol 2019;4:52.
}

Received: 25 November 2019; Accepted: 12 December 2019; Published: 05 October 2020

doi: $10.21037 /$ tgh.2019.12.09

View this article at: http://dx.doi.org/10.21037/tgh.2019.12.09

Alpha-fetoprotein (AFP) is the only tumor biomarker routinely used for the treatment of hepatocellular carcinoma (HCC). Even though this marker was discovered nearly 50 years ago and despite its lack of accuracy as diagnostic tool or screening test $32 \%$ to $59 \%$ of HCC patients have normal AFP levels), it appears to be a potential prognostic biomarker for HCC patients (1). Currently, the therapeutic indications of HCC are mostly based on outdated criteria (size and number of nodules) that do not reflect tumor aggressiveness. Indeed, a single small HCC node can be very aggressive, with or without vascular invasion, while one or more HCC nodules can be much less aggressive and have a better prognosis. Thus, the evolving profile of HCC is variable and unpredictable. There appear to be 3 types of tumors, fast, medium and slow, and a $1 \mathrm{~cm}$ tumor can take from 9.8 months to 10.9 years to reach $10 \mathrm{~cm}$, while the most progressive tumors go from 1 to $3 \mathrm{~cm}$ in 4.6 months (2). Therefore, the major concern of HCC aggressiveness is not only based on size and nodes number, but depends on other factors, such as AFP. AFP is strongly correlated to tumor aggressiveness $(1,3,4)$. Its levels are related with poorly differentiated HCC, tumor size and microvascular invasion $(1,5)$. Thus, the current issue is whether the pre-treatment AFP rate should be integrated into the treatment algorithm for HCC.

In liver transplantation, preoperative AFP rate is now included in several graft allocation such as in France or in United Kingdom because of its high influence on the prognosis of HCC patients (6-8). Duvoux et al. built a score which associate AFP with the number and the size of the HCC nodes (9). It allows to select patients with the best prognosis for liver transplant and excludes from the waiting list patients with high risk of early recurrence and poor prognosis. Thus, patients who were within the Milan Criteria but with an AFP rate of more than 1,000 ng/mL are excluded from access to the transplant, at least as long as their AFP rate is greater than $1,000 \mathrm{ng} / \mathrm{mL}$. This score has been validated (10) and the University of California, San Francisco (UCSF) team now applies a similar strategy (11).

For HCC resection, the interest of preoperative AFP rate before hepatectomy as a prognostic factor has been described by several authors (12-19). However, other studies have shown the contrary $(20,21)$. Thus, the use of preoperative AFP rate in the management of HCC patients who are candidates for liver resection remains therefore controversial. The article by Chan $e t a l$. published recently in Translational Gastroenterology and Hepatology is a retrospective cohort study evaluating the prognostic value of preoperative AFP rate in patients with resectable HCC (22). This study included 1,182 patients who underwent initial liver resection for HCC at Queen Mary Hospital in HongKong from March 1999 to March 2013. The authors compared the overall survival (OS) and the disease-free survival (DFS) of 3 groups of patients defined by their AFP level: $<20,20-400$ and $>400 \mathrm{ng} / \mathrm{mL}$. They also performed subgroup analysis according to tumor stage (7th edition UICC staging) and tumor size. Although this study is retrospective, it is of interest both by the issue raised which 
is still contradictory and by the large size of the cohort studied by the authors (1,182 patients).

The authors showed that a high AFP rate was correlated with poor OS and DFS, whereas patients with low AFP rate had better prognosis. The median DFS were 55.6, 25 and 8.4 months for HCC patients with AFP $<20,20-400$ and $>400 \mathrm{ng} / \mathrm{mL}$ respectively $(\mathrm{P}<0.001)$. The median OS were 132.9, 77.2 and 38.4 months respectively $(\mathrm{P}<0.001)$. In the subgroup analysis, the difference remained statistically significant for tumor stage (stages I-II $v s$. stages III-IV) and tumor size $(\leq 5 v s .>5 \mathrm{~cm}$ ), except for DFS in advanced disease. The conclusion of this study is that preoperative AFP rate is a major prognostic biomarker for predicting survival in patients with resectable HCC.

These findings are particularly interesting as they confirm on a very large population previous studies that showed similar conclusion (12-18). The thresholds used in the study of Chan et al. were AFP $<20,20-400$ and $>400 \mathrm{ng} / \mathrm{mL}$. However, in literature, the studies which focused on the correlation between pre-hepatectomy AFP and long-term prognosis used various different cutoff values for AFP (e.g., 20, 200, 400, 1,000 and 10,000 $\mathrm{ng} / \mathrm{mL}$ ). The variability of thresholds in these studies shows that it is difficult to determine an optimal cut-off. Nevertheless, the majority of authors agree that the prognosis of HCC is worse as soon as the AFP positivity threshold is reached (12-18). The population of this study was heterogenous and the 3 groups were not similar regarding their age, the size of the tumor, the tumor stage and the micro and macrovascular invasion, which was not surprising considering that AFP levels are correlated with poorly differentiated HCC, tumor size and microvascular invasion $(1,5)$. To reduce the impact of potential confounding factors in this retrospective observational study, it would have been interesting to realize a propensity score. Indeed, despite the need of decreasing the study population to perform a propensity score, it would have resulted in a homogeneous population, allowing to study the real impact of AFP regardless of other prognostic factors.

In their paper, Chan et al. raised the need to add preoperative AFP to the current staging systems and decision algorithms of HCC treatment. HCC prognosis being correlated to AFP, this biomarker should play a role in the decision of the various therapeutic strategy of patients with curative or palliative HCC, and not only before liver transplantation. Indeed, with rising evidences in preoperative AFP prognostic interest, it would be relevant for AFP to modulate therapeutic management strategies of HCC and the Barcelona Clinic Liver Center (BCLC) guidelines in order to improve the treatment of HCC patients $(7,23)$. Thus, the impact on clinical practice of preoperative AFP should be greater than it is at present. To confirm these results, it would be necessary to carry out a well-conducted multicentre prospective study on the impact of preoperative AFP in patients who are candidates for liver resection. Also, a new therapeutic strategy algorithm of HCC management treatment with the inclusion of preoperative AFP would be required to provide optimal care for HCC patients.

AFP remains a biomarker of choice in the therapeutic management of HCC. It has many defects but remains the only relevant biomarker routinely used in HCC patient's management. Therefore, at the time of advance in genetic and proteomic profiling in HCC $(24,25)$, the development of specific biomarkers is necessary, in order to offer an individualized therapeutic approach for each HCC patient.

\section{Acknowledgments}

None.

\section{Footnote}

Conflicts of Interest: The authors have no conflicts of interest to declare.

Ethical Statement: The authors are accountable for all aspects of the work in ensuring that questions related to the accuracy or integrity of any part of the work are appropriately investigated and resolved.

\section{References}

1. Charrière B, Maulat C, Suc B, Muscari F. Contribution of alpha-fetoprotein in liver transplantation for hepatocellular carcinoma. World J Hepatol 2016;8:881-90.

2. Sheu JC, Sung JL, Chen DS, et al. Growth rate of asymptomatic hepatocellular carcinoma and its clinical implications. Gastroenterology 1985;89:259-66.

3. Muscari F, Guinard JP, Kamar N, et al. Impact of preoperative $\alpha$-fetoprotein level on disease-free survival after liver transplantation for hepatocellular carcinoma. World J Surg 2012;36:1824-31.

4. Sherman M. The resurrection of alphafetoprotein. J Hepatol 2010;52:939-40.

5. Toro A, Ardiri A, Mannino M, et al. Effect of pre- and 
post-treatment $\alpha$-fetoprotein levels and tumor size on survival of patients with hepatocellular carcinoma treated by resection, transarterial chemoembolization or radiofrequency ablation: a retrospective study. BMC Surg 2014; $14: 40$.

6. Lai Q, Iesari S, Melandro F, et al. The growing impact of alpha-fetoprotein in the field of liver transplantation for hepatocellular cancer: time for a revolution. Transl Gastroenterol Hepatol 2017;2:72.

7. European Association for the Study of the Liver. Electronic address: easloffice@easloffice.eu, European Association for the Study of the Liver. EASL Clinical Practice Guidelines: Management of hepatocellular carcinoma. J Hepatol 2018;69:182-236.

8. Manas D, Burnapp L, Andrews PA. Summary of the British Transplantation Society UK Guidelines for Living Donor Liver Transplantation. Transplantation 2016;100:1184-90.

9. Duvoux C, Roudot-Thoraval F, Decaens T, et al. Liver transplantation for hepatocellular carcinoma: a model including $\alpha$-fetoprotein improves the performance of Milan criteria. Gastroenterology 2012;143:986-94.e3; quiz e14-15.

10. Notarpaolo A, Layese R, Magistri P, et al. Validation of the AFP model as a predictor of HCC recurrence in patients with viral hepatitis-related cirrhosis who had received a liver transplant for HCC. J Hepatol 2017;66:552-9.

11. Yao FY, Hameed B, Mehta N, et al. Response to letter to the editors. Liver Transpl 2014;20:1285.

12. Blank S, Wang Q, Fiel MI, et al. Assessing prognostic significance of preoperative alpha-fetoprotein in hepatitis B-associated hepatocellular carcinoma: normal is not the new normal. Ann Surg Oncol 2014;21:986-94.

13. Hsu CY, Liu PH, Ho SY, et al. Using nomogram of the Barcelona Clinic Liver Cancer system for treatment selection in patients with stage $\mathrm{C}$ hepatocellular carcinoma. BMC Cancer 2018;18:289.

14. Ikai I, Arii S, Kojiro M, et al. Reevaluation of prognostic factors for survival after liver resection in patients with hepatocellular carcinoma in a Japanese nationwide survey. Cancer 2004;101:796-802.

15. Ma WJ, Wang H, Teng L. Correlation analysis of preoperative serum alpha-fetoprotein (AFP) level and prognosis of hepatocellular carcinoma (HCC) after hepatectomy. World J Surg Oncol 2013;11:212.

16. Yamamoto K, Imamura H, Matsuyama $\mathrm{Y}$, et al. Significance of alpha-fetoprotein and des-gamma- carboxy prothrombin in patients with hepatocellular carcinoma undergoing hepatectomy. Ann Surg Oncol 2009;16:2795-804.

17. Santambrogio R, Opocher E, Costa M, et al. Hepatic resection for "BCLC stage A" hepatocellular carcinoma. The prognostic role of alpha-fetoprotein. Ann Surg Oncol 2012;19:426-34.

18. Nomura F, Ohnishi K, Tanabe Y. Clinical features and prognosis of hepatocellular carcinoma with reference to serum alpha-fetoprotein levels. Analysis of 606 patients. Cancer 1989;64:1700-7.

19. Bai DS, Zhang C, Chen $\mathrm{P}$, et al. The prognostic correlation of AFP level at diagnosis with pathological grade, progression, and survival of patients with hepatocellular carcinoma. Sci Rep 2017;7:12870.

20. Shim JH, Yoon DL, Han S, et al. Is serum alphafetoprotein useful for predicting recurrence and mortality specific to hepatocellular carcinoma after hepatectomy? A test based on propensity scores and competing risks analysis. Ann Surg Oncol 2012;19:3687-96.

21. Toyoda H, Kumada T, Kaneoka Y, et al. Prognostic value of pretreatment levels of tumor markers for hepatocellular carcinoma on survival after curative treatment of patients with HCC. J Hepatol 2008;49:223-32.

22. Chan MY, She WH, Dai WC, et al. Prognostic value of preoperative alpha-fetoprotein (AFP) level in patients receiving curative hepatectomy- an analysis of 1,182 patients in Hong Kong. Transl Gastroenterol Hepatol 2019;4:52.

23. Gómez-Rodríguez R, Romero-Gutiérrez M, Artaza-Varasa $T$, et al. The value of the Barcelona Clinic Liver Cancer and alpha-fetoprotein in the prognosis of hepatocellular carcinoma. Rev Esp Enferm Dig 2012;104:298-304.

24. Chan LK, Ng IO. Proteomic profiling in liver cancer: another new page. Transl Gastroenterol Hepatol 2019;4:47.

25. Schulze K, Nault JC, Villanueva A. Genetic profiling of hepatocellular carcinoma using next-generation sequencing. J Hepatol 2016;65:1031-42.

doi: $10.21037 / \operatorname{tgh} .2019 .12 .09$

Cite this article as: Muscari F, Maulat C. Preoperative alphafetoprotein (AFP) in hepatocellular carcinoma (HCC): is this 50-year biomarker still up-to-date? Transl Gastroenterol Hepatol 2020;5:46. 